\title{
Acquiring a Cognitive Skill With a New Repeating Version of the Tower of London Task
}

\author{
Marie-Christine Ouellet, École de psychologie, Université Laval \\ Miriam H. Beauchamp, Département de psychologie, Université de Montréal \\ Adrian M. Owen, MRC Cognition and Brain Sciences Unit, Cambridge \\ Julien Doyon, Département de psychologie, Université de Montréal
}

\begin{abstract}
A computerized version of the Tower of London task was used to investigate cognitive skill learning. Thirtysix healthy volunteers were assigned to either a random condition (nonrecurring problems), or to a sequence condition in which, unbeknownst to the subjects, a repeating sequence of three problems was presented. Indices of execution, planning, and total time, as well as number of moves performed, were used to measure behavioural change. Subjects' performance improved in both conditions across blocks of practice. A distinct learning effect related to the repeating sequence was also observed. This suggests that a specific skill that reflects procedural learning of the strategies, rules, and procedures pertaining to repeating problems can develop over and above a more general skill at solving cognitive planning problems with practice.
\end{abstract}

Cognitive skill learning can be defined as the process by which rules, procedures, and strategies relevant to the performance of a task demanding mental operations come to be combined and used effectively following repeated practice. A broad range of paradigms have been used to study the time course of learning and the critical parameters required to trigger the acquisition of new cognitive abilities, including tasks as varied as those involving mnemonic abilities (Ericsson, 1985), artificial grammar (see Knowlton \& Squire, 1994 for a review), mathematics and arithmetic (Campbell \& Graham, 1985; Charness, Milberg, \& Alexander, 1988; McGlinchey-Berroth, Milberg, \& Charness, 1989; Pauli et al., 1994), computer use and programming (Anderson, Farrell, \& Sauers, 1984; Glisky \& Schacter, 1988, 1989; Glisky, Schacter, \& Tulving, 1986; Pirolli \& Anderson, 1985; Squire \& Frambach, 1990), as well as those requiring planning and problem-solving abilities (Butters, Wolfe, Martone, Granholm, \& Cermak, 1985; Daum et al., 1995; Fasotti, Eling, \& van Houtem, 1994; Saint-Cyr, Taylor, \& Lang, 1988). In general, the results of these studies have shown that normal control subjects become more efficient at performing cognitive tasks as a function of practice. Indeed, learning on these types of tasks is usually observed through test performance and is measured by a gradual reduction in reaction time, a decrease in the number of errors, and/or a reduction in the number of trials to reach criterion.

Theories of skill learning provide a useful conceptual framework to understand the processes involved in the acquisition of cognitive skills. For example, the models elaborated by Fitts (1962) and Anderson (1990) propose the existence of three distinct stages in the development of a cognitive skill: 1) a declarative or cognitive stage, 2) a compilation or associative stage, and 3) a tuning or autonomous stage. In the first stage, skills develop through the use and integration of declarative knowledge in the form of instructions and essential information pertaining to the performance of the task at hand. Anderson (1990) has argued that, at this stage, learners are using domain-general problemsolving procedures that are provided by accumulating examples of possible solutions or mental operations, which can then be stored as declarative knowledge for future use. It is believed that this knowledge can speed up performance because, rather than having to go through all the processes involving the application of rules and procedures of a given task, a particular strategy can be retrieved directly from memory (Anderson \& Fincham, 1994; Anderson, Fincham, \& Douglass, 1997; Pirolli \& Anderson, 1985). Thus, at this stage, changes are thought to be related to the amount of declarative information that learners acquire with the development of a new skill, the knowledge base becoming greater and better organized with experience. Evidence for such changes comes from studies that have investigated the differences between experts and novices in various cognitive domains such as chess playing (DeGroot, 1965) or physics (Heller \& Reif, 1984; Larkin, 1985). For example, it has been shown that experienced chess players are more efficient than beginners because they 
rely heavily on explicit knowledge acquired from previously encountered game configurations.

Despite the fact that explicit knowledge seems essential in the acquisition of a variety of cognitive skills, especially in the initial phases of learning, there is also ample evidence that some cognitive skills can be acquired through nonconscious or implicit processes. In 1967, Reber showed that normal subjects became increasingly efficient at classifying either grammatical or nongrammatical letter strings although they were not aware of the underlying rules governing the structure of these letter strings. In this artificial grammar task, subjects learned to exploit regularities or structure in the stimuli presented in order to improve their performance, yet they seemingly had no conscious access to the rules on which they based their classification. Other studies using probabilistic learning (Reber \& Millward, 1971) simulated economic systems (Berry \& Broadbent, 1984), or target location learning (Lewicki, Hill, \& Bizot, 1988) also indicated that subjects are sensitive to underlying rule systems or relationships between events without declarative knowledge of the existence of such rules or relationships.

Studies of amnesic patients have also contributed to show that cognitive skills may be learned implicitly. Whereas the acquisition of new explicit knowledge is impaired in amnesia, implicit learning (i.e., skill acquisition, conditioning, priming, and habit formation) is spared. Cohen and collaborators reported that the amnesic patient H. M. was able to learn to solve a puzzle, the Tower of Hanoi task, as fast as control subjects, and to remember how to solve the puzzle despite having no recollection of ever having seen the test (Cohen \& Corkin, 1981; Cohen, Eichenbaum, Deacedo, \& Corkin, 1985). Similarly, Knowlton, Ramus, and Squire (1992) demonstrated that amnesic patients performed as well as normal control subjects on an artificial grammar task, despite the fact that they were poor at recognizing the exemplars that had been presented. Thus, amnesic patients seem able to acquire cognitive skills without going through a declarative stage as proposed by Anderson's model.

The second stage of cognitive skill learning, proposed by Fitts and Anderson, is an associative phase where knowledge is thought to be converted, through different processes, into procedures specific to the domain in which the skill is acquired. This stage is also believed to be directly related to the execution of a skill. Anderson (1990) has described several learning mechanisms (e.g., composition and proceduralization) by which procedures are combined to generate more efficient strategies to perform a cognitive task, while others have proposed that, at this phase, components of the task are restructured into more complex units, thereby allowing a further speed-up in performance (Cheng, 1985; Rosenbloom \& Newell, 1987). Empirical evidence supporting the existence of a reorganization of components of a skill during the acquisition process comes, for example, from studies which have shown that normal control subjects become more efficient with practice at putting together the different steps of an algorithm in mental calculation (Charness \& Campbell, 1988; Charness et al., 1988), as well as at solving geometry problems (Anderson, Greeno, Kline, \& Neves, 1981).

Finally, at the third stage, or autonomous phase, skills are believed to be refined and to become more automated. Mechanisms like tuning (Anderson, 1990) and automatization (Logan, 1985, 1988; Shiffrin \& Dumais, 1981) have been proposed to describe the processes that occur at this stage of learning. Studies using dual-task paradigms have provided insight into this phase of skill acquisition. They suggest that the automatization of cognitive skills is characterized by a reduction of the demands placed on cognitive resources and, in particular, on attentional and working memory capacities (Carlson, Sullivan, \& Schneider, 1989; Heuer, 1996; Woltz, 1988; Yap \& van der Leij, 1994).

One category of cognitive skills that has received much attention from the scientific community relates to the ability to solve complex problems. The main reason for emphasizing the study of this type of skill pertains to the fact that nearly all human cognitive activities contain some aspects of problem-solving (Anderson, 1990). To study the cognitive characteristics involved in the acquisition of new problem-solving skills with practice, some researchers have relied on the Tower of Hanoï puzzle (Anzai \& Simon, 1979). In this task, subjects need to develop and carry out a plan to displace a stack of disks on three pegs from a starting-position to a goal-position, by moving only one disk at a time and never placing a larger disk over a smaller one. Performance on this task is usually measured by recording the total number of displacements used by the subject to achieve the goal position. Early indications that the Tower of Hanoï could be used as a cognitive skill learning task were provided by Cohen and collaborators (Cohen \& Corkin, 1981; Cohen et al., 1985). Several subsequent studies have shown that normal control subjects exhibit procedural learning on this task, as evidenced by a significant decrease in the number of superfluous moves used to find the optimal solution when they are repeatedly exposed to the puzzle (Beatty et al., 1987; Butters et al., 1985; Cohen et al., 1985; Saint-Cyr et al., 1988). However, one disadvantage of using the Tower of Hanoï task to study skill learning is that on every practice trial, the subject is 
presented with the exact same problem. This makes the learning very specific to one particular solution, thereby limiting the ecological validity of the task in a skill learning context. Furthermore, repeated practice of the Tower of Hanoï implies searching for a repeating strategy, which can eventually lead to explicit knowledge of this particular strategy. Thus, the question that arises is whether procedural learning can still occur when subjects have acquired declarative knowledge of the solution to the puzzle and can merely apply a known sequence of displacements, without having to engage in the planning and problem-solving procedures necessary to initially discover and carry out the solution to the problem.

To overcome the restrictions associated with the Tower of Hanoï puzzle, we sought to develop a problem-solving task that would allow comparison with findings from these studies, while taking into consideration the limitations mentioned above, in particular, through the use of a variety of problems requiring different solutions. To this end, we used a computerized repeating version of the Tower of London task (initially developed by Shallice [1982] and adapted by Robbins and colleagues [Morris et al., 1988; Owen, Downes, Sahakian, Polkey, \& Robbins, 1990; Owen, Doyon, Petrides, \& Evans, 1996; Owen et al., 1992]) to study the time course of learning, as well as the cognitive procedures necessary to solve Tower of London problems effectively. The Tower of London task was chosen because, like most real-life cognitive skills, this task requires a complex amalgam of different cognitive processes used in conjunction. These include processes such as short-term spatial memory, working memory and planning, the generation and sequencing of responses, the active search of possible solutions, the analysis of visuospatial information, sustained and directed attention, and visual imagery (Baker et al., 1996; Owen, 1997; Owen \& Doyon, 1999; Owen et al., 1990, 1992, 1996; Shallice, 1982; Vanier, 1991). More specifically, the Tower of London task consists of a series of visual problems in which subjects are asked to move coloured balls in order to reproduce a goal configuration. Several "legal move" instructions restrict the type of moves that can be carried out to arrive at the desired solution, hence forcing the use of planning and problem-solving strategies. Previous work with the Tower of London task has demonstrated that while the time to plan and to execute the problems generally increases significantly with the level of difficulty of the task, the proportion of problems completed using an optimal solution (i.e., employing the minimum number of moves) decreases as problems get more difficult (Owen et al., 1990, 1992, 1996). It is important to note that previous studies using this task have measured the performance of control subjects and patient groups at one point in time. As yet, no study has investigated the changes in performance over time and with practice on the Tower of London task in order to measure cognitive skill learning. While it may initially be necessary for participants to learn legal moves for solving the tasks (e.g., they are told they cannot move a ball if another is placed directly above it), there is no one solution that can be applied to all problems, thus making learning of this task primarily procedural in nature.

The objectives of the present study were three-fold. The first was to evaluate the time course of learning associated with solving Tower of London problems in order to determine the utility of this task as a measure of cognitive skill acquisition. We hypothesized that general skill learning would occur with repetitive presentation of different Tower of London problems. The second objective was to describe the nature of the cognitive processes that allow subjects to develop such a skill by looking at different dependent measures of performance over time. We predicted that, with practice, subjects would become more efficient at planning a solution to the problems, and would also carry out these solutions more effectively, as shown by a decrease in the time needed to complete the planned solution, as well as a reduction in the number of superfluous or inefficient moves. Finally, the third objective was to determine whether the inclusion of an embedded repeating sequence of problems of the Tower of London task would produce an enhancement of performance specific to this sequence. To this end, a sequence learning paradigm based on the one described in Nissen and Bullemer's (1987) seminal studies of visuomotor sequence acquisition was employed to measure the effect of being exposed to a sequence of three repeating Tower of London problems during learning. We predicted that subjects presented with a repeating sequence of problems would demonstrate further improvement in performance on the repeating trials, thus reflecting specific procedural learning of the strategies, rules, and procedures necessary to solve efficiently the sequence of problems.

Method
Subjects
Thirty-six healthy volunteers ( 20 female, 16 male)
participated in this study. Subjects with any history of a
psychiatric or neurological disorder were excluded
from the study. They were aged between 18 and 42
years $(M=24.42$ years, $S D=4.66)$ and had completed
between 11 and 16 years of education $(M=14.89$ years,
$S D=1.63)$. Thirty-four subjects were right-handed and
two were left-handed. All subjects had a visual memory


TABLE 1

Subject Characteristics in the Two Experimental Conditions

\begin{tabular}{lcc}
\hline & $\begin{array}{c}\text { Random Condition } \\
(\mathrm{n}=18)\end{array}$ & $\begin{array}{c}\text { Sequence Condition } \\
(\mathrm{n}=18)\end{array}$ \\
\hline Age (years) & 24.17 & 24.67 \\
$M$ & 3.5 & 5.7 \\
$S D$ & & \\
Education (years) & 15.22 & 14.56 \\
$M$ & 1.6 & 1.6 \\
$S D$ & $10 / 8$ & $10 / 8$ \\
Sex (female/male) & $17 / 1$ & $17 / 1$ \\
Dominance (right/left) & & \\
Block span score & 15.05 & 14.93 \\
$M$ & 2.2 & 2.3 \\
$S D$ & & \\
\hline
\end{tabular}

span within normal limits $(M=15.00, S D=2.18)$ as measured by the Wechsler Memory Scale - Revised Test (Wechsler, 1987). These results are summarized in Table 1. Also, all subjects had normal or corrected-tonormal vision and reported having normal colour perception and discrimination. Subjects gave their informed written consent before participating in this study. This experiment was approved by the Ethics Committee of the Psychology Department at Laval University.

\section{Material}

Cognitive skill learning was measured using a computerized repeating version of the Tower of London task (Owen et al., 1990, 1992, 1996; Shallice, 1982). This task was programmed in Visual Basic and was administered with a Compaq 1210 Presario computer equipped with a MicroTouch Touchscreen mounted on an IBM screen. The program recorded time measures (i.e., total, initial planning, and execution times) that were precise to the millisecond.

Subjects were seated directly in front of the screen and asked to rest their dominant elbow on a foam pad located on a table and to touch a target on a touch-sensitive screen. The distance and height of the screen were adjusted to minimize the physical demands of the task, and to allow the most comfortable position possible throughout the testing session. All subjects used their dominant hand to respond to the stimuli.

\section{Stimuli}

Subjects were presented with two displays of coloured balls (each approximately three centimeters in diameter). The set on top of the screen corresponded to a model display, while the set at the bottom corresponded to a working display. Each set was composed of three coloured balls (blue, red, and green) that could be placed in any of three pockets, which could contain, respectively, only one, two, and three balls. Balls could be moved to empty spaces within these pockets. To move a ball, subjects had to touch it on the screen with the index finger of the dominant hand, and then touch one of the vacant positions. Once selected, the ball began to flash, indicating that it had been activated and that it was ready to be moved to another location.

Subjects were asked to adhere to the following instructions pertaining to legal moves when displacing balls. First, they were not allowed to move a ball if another one was placed directly above it. Second, an illegal move was made if participants clicked an available position that was in the same column as the flashing ball. Third, they were not allowed to move a ball to a location that was already occupied. The program was set such that it would not allow illegal moves and would produce a warning sound when subjects did not conform to the instructions for legal moves. The program counted errors when either an illegal move was made or when a participant selected and then deselected a ball.

The positions of the coloured balls in both the model and working displays were predetermined in order to create problems of different levels of complexity. Unlike previous computerized versions of the Tower of London where only the model display varied and the starting position remained identical from one problem to the other, the present version of the task allowed for various combinations of working and model displays. Before each problem, subjects were told the minimal number of moves needed to solve the problem. Subjects were specifically instructed to try to plan the solution mentally before they started displacing any balls in order to reproduce the model configuration in the minimum number of moves possible.

\section{Procedure}

Subjects were trained on the Tower of London task within a single session that lasted approximately 90 minutes. The subjects were given standard instructions for the task and informed of legal moves, followed by a brief demonstration using simple problems. They were then asked to execute a series of six trials of increasing levels of difficulty (1-, 2-, 3-, 4-, 5-, and 6move problems) to ensure that the instructions were well understood (familiarization phase), hence allowing only minimal practice before training trials began. None of the problems completed in the familiarization phase were presented in the learning phase.

Because of the large number of problems administered during training, problems had to be selected from 
a)

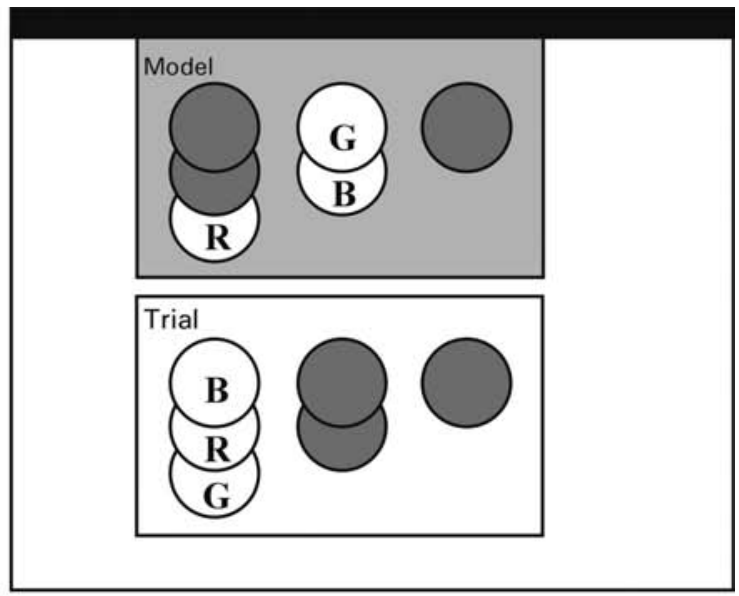

b)
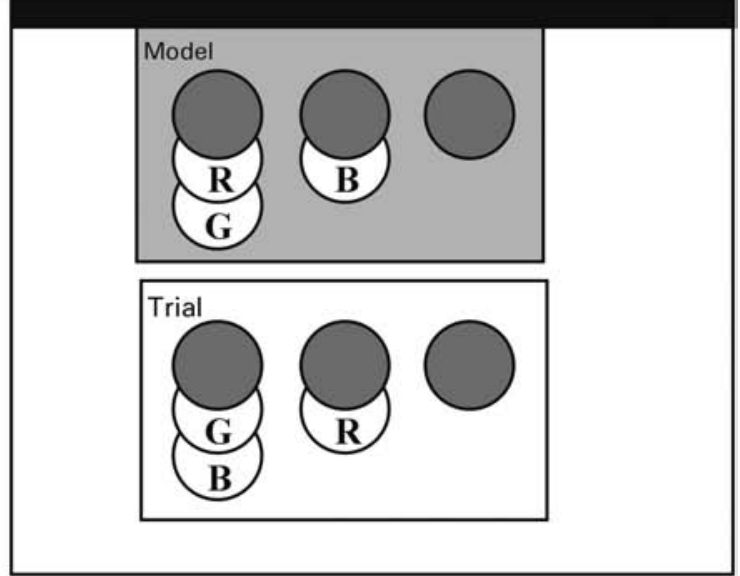

c)
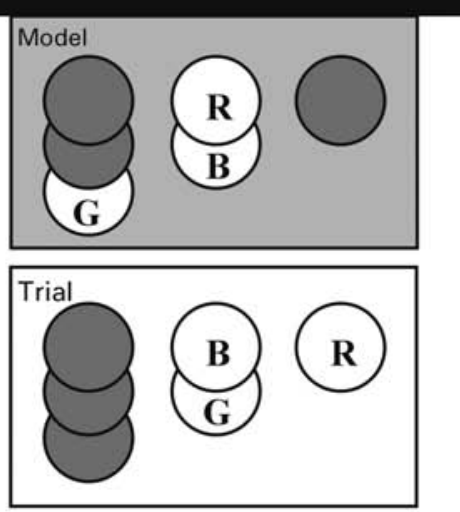

Figure 1. Examples of problems of the Tower of London at three levels of difficulty: (a) four-move problem, (b) five-move problem, and (c) six-move problem. $(\mathbf{R}=\mathrm{red}, \mathbf{B}=$ blue, $\mathbf{G}=$ green $)$.

three different levels of difficulty. Each trial was composed of problems that required four, five, or six moves to be solved (see Figure 1). A four-move problem was always followed by a six-move problem, which was then followed by a five-move problem. All subjects completed five blocks of 15 learning trials.
Therefore, they completed a total of 75 problems, 25 at each level of complexity. Subjects were randomly assigned to one of two conditions, either a random condition or a sequence condition. In the random condition, the subjects were presented with nonrecurring problems that were always different in the five blocks of trials. These were chosen to be as different from one another as possible in terms of the steps involved in solving the problems. As in the random condition, subjects in the sequence condition were also presented with two blocks of trials comprising different problems, one at the beginning (Block 1) and one at the end (Block 5) of the training session. However, unbeknownst to the subjects, in Blocks 2, 3, and 4 of the training session, a repeating sequence of three problems (one 4-move, one 6-move, and one 5-move) was incorporated. In total, subjects in the sequence group were therefore exposed 15 times to the sequence of three problems. In order to minimize the chance of subjects noticing and trying to learn the repeated problems, consecutive presentations of the sequence of problems always involved a different combination of colours (i.e., although the problems looked different in terms of colour configuration from one trial to another, they required the exact same moves to be solved).

At the end of training, subjects in the sequence condition were asked to answer a short questionnaire to qualitatively assess their declarative knowledge of the repeating problems. This questionnaire comprised the following questions: 1) Did you notice anything particular during the execution of the Tower of London task? 2) Do you think that all of the problems were different from one another? 3) Do you think that some of the problems were repeated? 4) Did you notice a sequence of problems that repeated over and over? and 5) Did you notice anything different between the last block of trials and the other blocks of practice trials? When subjects noticed that a sequence of problems was repeated, they were asked to give more details (i.e., the minimum number of moves, the starting configuration of the balls in the working or the model display, and the specific moves that had to be executed).

\section{Performance Indices and Data Analyses}

Four learning indices were used to measure the subjects' performance on the Tower of London problems: 1) the total time in seconds used to complete a problem, running from the initial presentation of the problem to the completion of the last move, 2) the initial planning time in seconds, extending from the initial presentation of the problem until the first touch on the screen was made, 3) the execution time in seconds, defined by the time elapsed from the first touch until the completion of the problem, and 4) the total number 
of moves used to complete the problem.

The behavioural data were first examined using Bonferroni t-tests on the first and last blocks of trials to determine whether both groups of subjects had the same initial and final level of performance. Furthermore, separate 2 x 5 (Condition x Block) twoway analyses of variance (ANOVAs) were carried out for each dependent measure, in which Condition was treated as a between-group factor, while Block was treated as a within-subject factor. The degrees of freedom in the ANOVAs were corrected with the Greenhouse-Geisser procedure for possible heterogeneity of covariance. The alpha level was set at .05.

In addition, planned comparisons were used to provide a more detailed examination of the pattern of results. Planned orthogonal contrasts, corrected with the Bonferroni procedure for multiple comparisons, were carried out for each dependent variable to verify the following a priori hypotheses:

a) The subjects in both the random and sequence conditions would show significant improvement in performance on the task with practice from Block 1 to Block 5.

b) The subjects' performance would improve significantly more from Block 2 to Block 4 in the sequence condition than in the random condition.

c) The subjects' performance would deteriorate significantly when the sequence was removed (i.e., from Block 4 to Block 5) in the sequence condition, but not in the random condition.

Finally, exploratory analyses were performed on the number of errors and by level of difficulty.

\section{Results}

Separate t-tests revealed that the subjects included in the random and sequence conditions did not differ with respect to their mean age, level of education, and performance on the Visual Memory Span subtest of the Wechsler Memory Scale - Revised (see Table 1). The gender distribution was identical for both groups. The behavioural findings with respect to different dependent measures are shown in Figures 2, 3, 4, 5. A summary of the results is presented in Table 2 .

Bonferroni t-tests performed on the first block of trials indicate that subjects in both conditions performed at an equivalent level at the beginning of training in terms of the total time, $t(17)=-1.99, p>.05$, CI: -8.02 , 2.84 , initial planning time, $t(17)=-1.16, p>.05$, CI: $-3.01,3.20$, execution time, $t(17)=-1.18, p>.05$, CI: $-7.02,1.65$, and number of moves, $t(17)=0.24, p>.05$, CI: $-.50,0.70$. Furthermore, there was no significant difference in performance between groups on the last

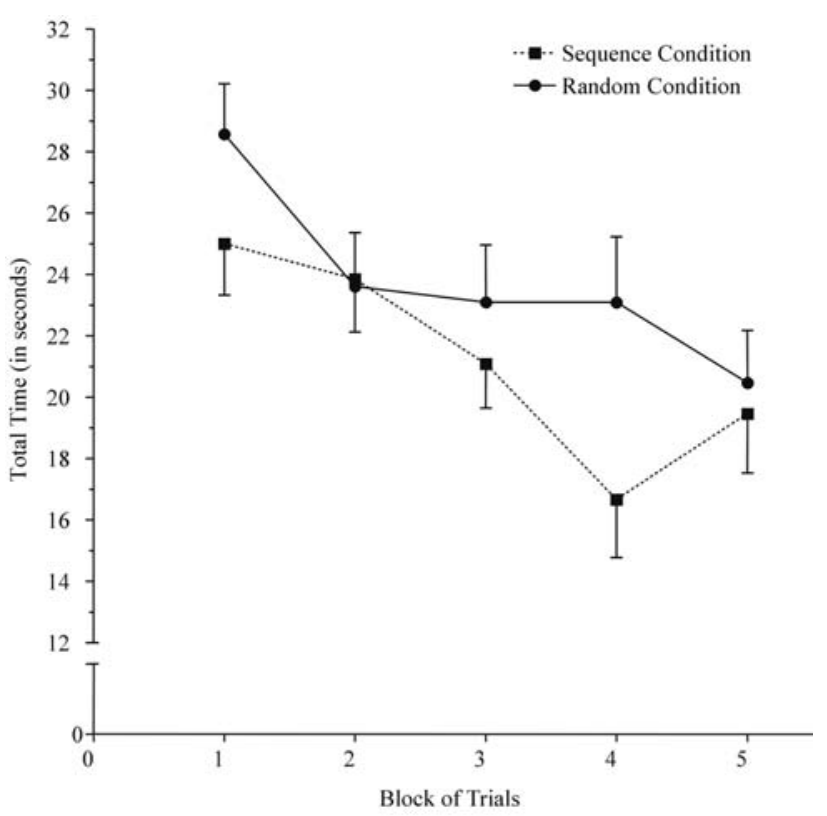

Figure 2. Results showing the mean total time taken to complete the Tower of London problems in both the random and sequence conditions across the five blocks of trials. Vertical lines depict standard errors of the means.

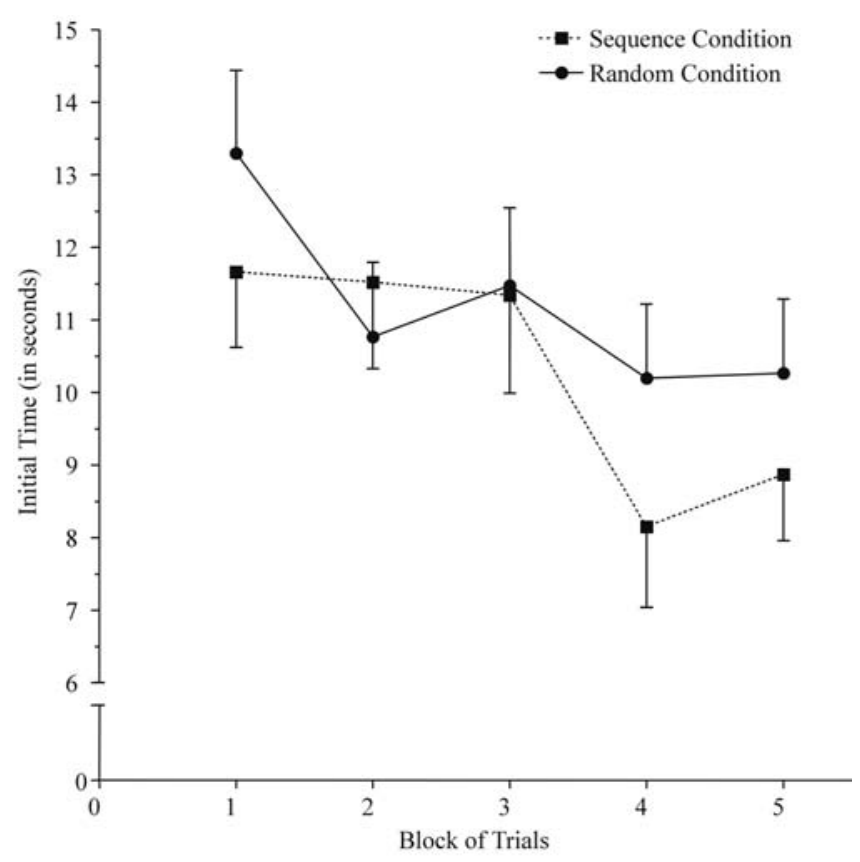

Figure 3. Results showing the mean initial planning time taken to complete the Tower of London problems in both the random and sequence conditions across the five blocks of trials. Vertical lines depict standard errors of the means. 


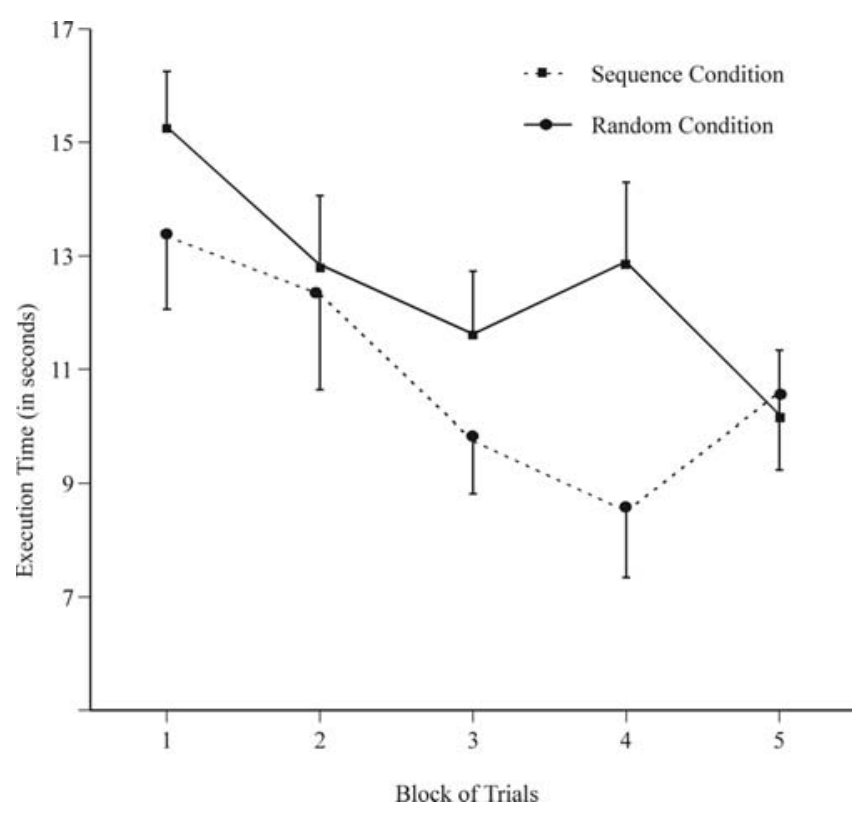

Figure 4. Results showing the execution time taken to complete the Tower of London problems in both the random and sequence conditions across the five blocks of trials. Vertical lines depict standard errors of the means.

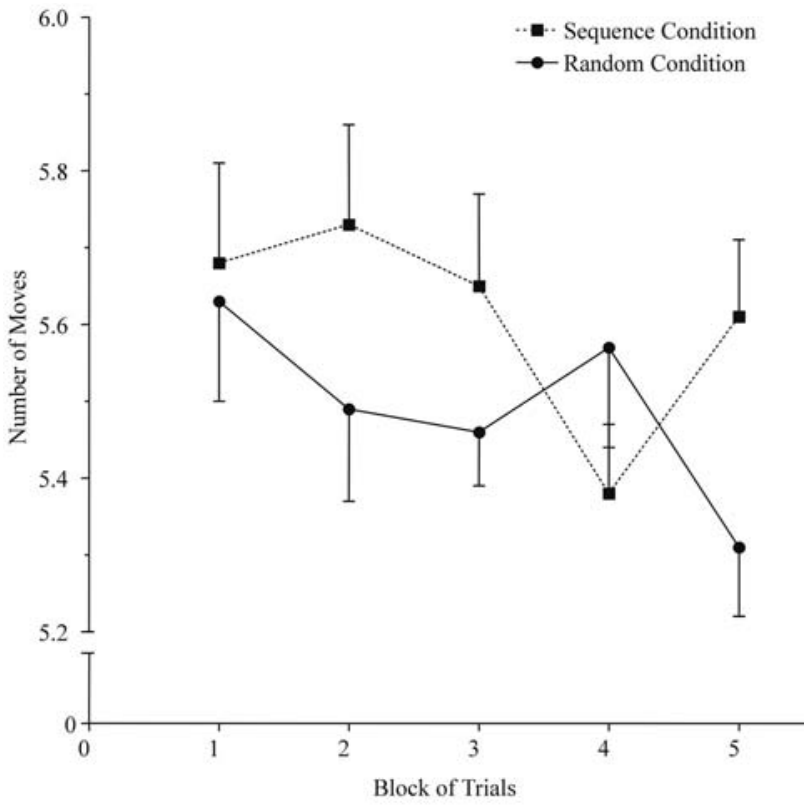

Figure 5. Results showing the mean number of moves executed to complete the Tower of London problems in both the random and sequence conditions across the five blocks of trials. Vertical lines depict standard errors of the means.

TABLE 2

Confidence Intervals Obtained in Pairwise Comparisons for the Four Dependent Measures

\begin{tabular}{|c|c|c|c|c|c|c|}
\hline \multirow[b]{2}{*}{ Comparison } & \multicolumn{3}{|c|}{$\begin{array}{c}\text { Random Condition } \\
F(1,17) \\
95 \% \text { Confidence Interval of the Difference }\end{array}$} & \multicolumn{3}{|c|}{$\begin{array}{c}\text { Sequence Condition } \\
F(1,17) \\
95 \% \text { Confidence Interval of the Difference }\end{array}$} \\
\hline & $\begin{array}{l}\text { Blocks } \\
1 \text { vs. } 5\end{array}$ & $\begin{array}{l}\text { Blocks } \\
2 \text { vs. } 4\end{array}$ & $\begin{array}{l}\text { Blocks } \\
4 \text { vs. } 5\end{array}$ & $\begin{array}{l}\text { Blocks } \\
1 \text { vs. } 5\end{array}$ & $\begin{array}{l}\text { Blocks } \\
2 \text { vs. } 4\end{array}$ & $\begin{array}{l}\text { Blocks } \\
4 \text { vs. } 5\end{array}$ \\
\hline Total time & $(4.83,11.39)^{*}$ & $(-2.30,3.34)$ & $(0.31,4.95)$ & $(1.99,9.10)^{*}$ & $(4.00,10.36)^{*}$ & $(-5.02,-0.58)^{*}$ \\
\hline Initial planning time & $(1.22,4.84)^{*}$ & $(-0.83,1.97)$ & $(-0.97,0.83)$ & $(0.92,4.67)^{*}$ & $(1.09,5.66)^{*}$ & $(-2.62,1.18)$ \\
\hline Execution time & $(2.99,7.16)^{*}$ & $(-2.28,2.18)$ & $(0.33,5.07)$ & $(0.19,5.31)$ & $(1.08,6.53)^{*}$ & $(-3.72,-0.43)^{*}$ \\
\hline Number of moves & $(0.12,0.52)^{*}$ & $(-0.30,0.14)$ & $(0.02,0.51)$ & $(-0.10,0.25)$ & $(0.14,0.57)^{*}$ & $(-0.37,-0.89) *$ \\
\hline
\end{tabular}

$* p<.05$ with critical value of Bonferroni $F(1,17)=7.05$.

block of trials on any of the dependent measures, total time, $t(17)=-0.45, p>.05$, CI: $-7.49,3.68$, initial planning time, $t(17)=-1.01, p>.05$, CI: $-5.41,1.24$, execution time, $t(17)=0.23, p>.05$, CI: $-3.70,4.05$, and number of moves, $t(17)=1.87, p>.05$, CI: $-0.35,0.87$, thus suggesting that subjects in both conditions achieved similar levels of performance in the random blocks.

\section{Total Time}

A two-way ANOVA with repeated measures (Condition $\mathrm{x}$ Block) performed on the total time to complete the Tower of London problems over the five blocks of trials yielded a significant main effect of Block, $F(3,92)=18.50, p<.01$, and a significant Condition $\times$ Block interaction, $F(3,92)=3.67, p<.05$. By contrast, the main effect of Condition was not significant, $F(1,23)=1.31, p>.05$.

Planned comparisons with Bonferroni corrections were used to test the a priori hypotheses. As predicted, the analyses revealed that subjects in both the random, $F(1,17)=27.20, p<.01$, and sequence, $F(1,17=10.82$, $p<.01$, conditions required significantly less time to complete the problems in Block 5 than in Block 1. Furthermore, subjects in the sequence, $F(1,17)=22.72$, 
TABLE 3

Mean Number of Errors (and Standard Error) Made by Participants in Both Conditions Over the Course of Learning

\begin{tabular}{cccccccc}
\hline & Condition & Block 1 & Block 2 & Block 3 & Block 4 & Block 5 \\
\hline \multirow{2}{*}{ Illegal Moves } & Random & $1.56(0.54)$ & $0.83(0.36)$ & $1.22(0.38)$ & $1.39(0.82)$ & $0.67(0.29)$ \\
& Sequence & $1.06(0.35)$ & $1.56(0.43)$ & $1.33(0.40)$ & $1.39(0.33)$ & $1.67(0.31)$ \\
\multirow{3}{*}{ De-selection } & & & & & & \\
& Random & $2.80(0.45)$ & $2.33(0.48)$ & $3.00(0.72)$ & $3.31(1.07)$ & $2.89(0.58)$ \\
& Sequence & $3.45(0.57)$ & $3.38(0.63)$ & $2.27(0.30)$ & $3.00(0.41)$ & $2.46(0.57)$ \\
\hline
\end{tabular}

$p<.01$, but not those in the random condition, $F<1, p$ $>.05$, needed significantly less time to complete the problems from Block 2 to Block 4. Finally, only the subjects in the sequence condition took significantly more time to complete the problems in Block 5 than in Block 4, $F(1,17)=7.09, p<.05$, indicating that their performance deteriorated when the sequence was removed.

\section{Initial Planning Time}

A second two-way ANOVA with repeated measures (Condition $\mathrm{x}$ Block) was performed over the five blocks of trials on the measure of initial planning time before completing the first move on the Tower of London problems. This analysis showed a main effect of Block, $F(3,88)=10.98, p<.001$, indicating that, with practice, subjects took less time before completing their first moves. No effect of Condition was observed, $F(1$, $22)<1, p>.05$, and the Condition $\times$ Block interaction also failed to reach significance, $F(3,88)=1.99, p>.05$.

Planned comparisons using the same orthogonal contrasts as for the "Total Time" measure of performance were again applied to verify our three a priori hypotheses. Again, the results of these analyses revealed a significant decrease in initial planning time from Block 1 to Block 5 in both the random, $F(1,17)=$ $12,44, p<.01$, and sequence, $F(1,17)=9.89, p<.01$, conditions. In accordance with our hypothesis, a significant difference was found between Blocks 2 and 4 in the sequence condition, $F(1,17)=9.71, p<.01$, but not in the random condition, $F(1,17)<1, p>.05$, suggesting a greater improvement in performance when a sequence of problems was presented than when problems were different on each trial. Contrary to our prediction, however, the performance of subjects in the sequence condition did not change significantly from Block 4 to Block 5, $F<1, p>.05$. Nevertheless, taken together, these results point to an effect of the repeating sequence on the initial planning time needed before completing the Tower of London problems.

\section{Execution Time}

Again, a two-way repeated measures ANOVA (Condition $\mathrm{x}$ Block) was used to examine the time needed to solve the Tower of London problems. We observed a main effect of Block, $F(3,117)=101.77, p<$ .01 , as well as a significant Condition $\times$ Block interaction, $F(3,117)=29.37, p<.05$.

Planned comparisons showed that subjects in the random condition decreased their execution time from Block 1 to Block 5, $F(1,17)=26.58, p<.01$, whereas subjects in the sequence group did not $(p>.05)$. This result may be explained by the fact that subjects in this last group showed a significant increase in execution time from Block 4 to Block 5, $F(1,17)=7.13, p<.05$, whereas no such increase was seen in the random group, $F(1,17)=5.79, p>.05$. Furthermore, the effect of the repeating sequence was also confirmed by a significant decrease in the time used to execute the solutions to the Tower of London problems from Block 2 to Block 4 in the sequence condition, $F(1,17)=8.72, p<$ .01 , but not in the random condition, $F(1,17)<1, p>$ .05 .

\section{Number of Moves}

A two-way repeated measures ANOVA performed on the number of moves needed to complete the Tower of London problems in the five blocks of trials revealed a significant Condition $\times$ Block interaction, $F(3,118)=$ $3.29, p<.05$. The main effects of Block, $F(3,118)=$ $2.47, p>.05$, and Condition, $F(1,29)<1, p>.05$, however, did not reach significance. Planned comparisons showed that only subjects in the random condition decreased their number of moves to complete the problems with practice from Block 1 to Block 5 . However, subjects in the sequence condition needed significantly fewer moves from Block 2 to Block 4 when the sequence was presented, $F(1,17)=11.89, p$ $<.01$, while subjects in the random condition did not, $F(1,17)<1, p>.05$. These results suggest that the presentation of the sequence had an effect on the number of moves required to complete the problems. Furthermore, subjects in the sequence condition used significantly more moves to complete the problems in Block 5 than in Block $4, F(1,17)=11.72, p<.01$, suggesting that their performance decreased once the sequence was removed. No such decrease was seen in the random condition, $F(1,17)=5.08, p>.05$. 


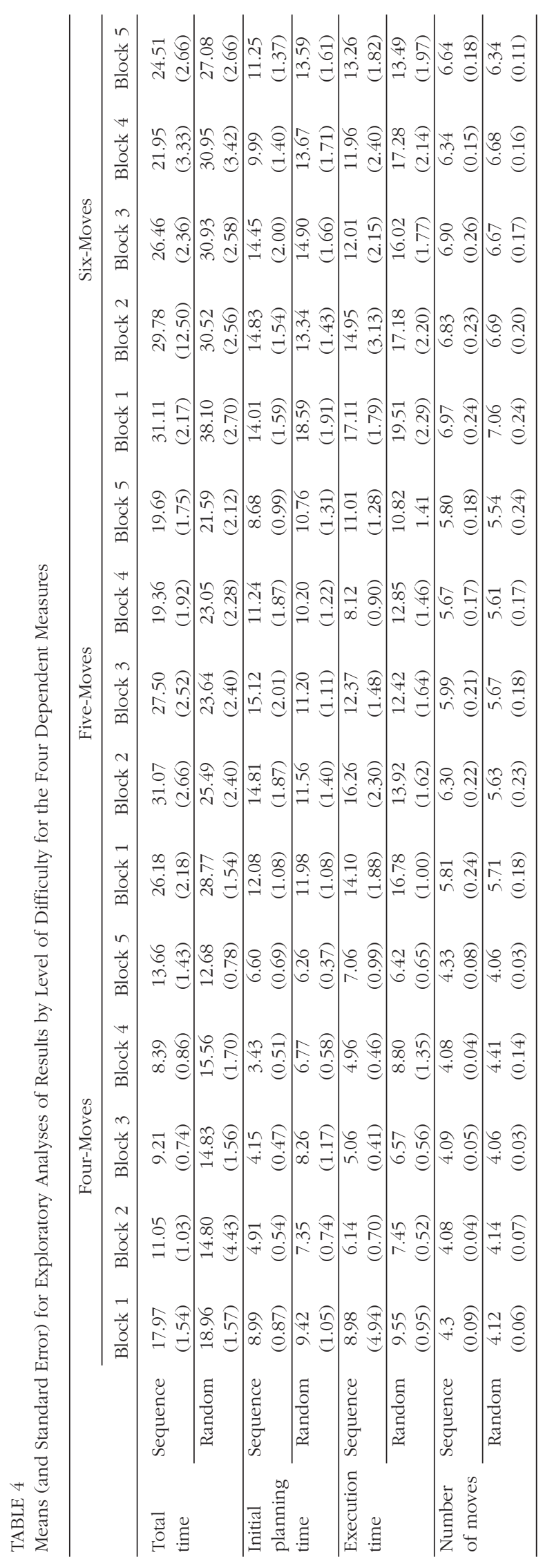

Errors

The number of errors made was highly variable from one participant to the next. Table 3 presents a summary of errors by type. Two-way Condition $\mathrm{x}$ Block analyses of variance revealed no significant change in the number of errors made over the course of learning, $F(3,97)=0.31, p>.05$, no interaction, $F(3,97)=1.22, p>.05$, and no difference between groups, $F(3,97)=0.01 p>.05$. This is not surprising given that participants were specifically instructed not to perform illegal moves and generally adhered to this, thus making very few errors. The most common type of error made was to select and then de-select a flashing ball, which can either be a result of impulsivity or a change in the problem-solving/planning process.

\section{Analyses by Level of Difficulty}

Exploratory analyses were performed on the data to determine how the level of difficulty of the problems influenced learning. The pattern of results was not always consistent from one dependent variable to another or from one level of difficulty to another, thus rendering the interpretation of results quite difficult (see Table 4). Furthermore, the power of these analyses is reduced as only 15 problems could be considered for each level of difficulty. In general, however, a significant learning effect was observed regardless of the level of difficulty (main effects of Block were significant for Think Time, Total Time, and Execution Time). Group x Block interactions were found significant for the four- and five-move problems, yet group effects were only seen for the four-move problems. This suggests that the effect of the sequence was stronger in the easier problems.

\section{Declarative Knowledge of the Sequence}

Analysis of the subjects' responses on the short questionnaire revealed that though subjects in the sequence condition were aware that certain problems were repeated, only four of the eighteen subjects were able to relate any specific information about the repeating problems. For example, they noticed a difference between the conditions of presentation of the problems in Blocks 4 and 5, and realized that they had completed the same configurations of problems that changed only with respect to colour. Based on these findings analyses were run again excluding the performance of these four subjects in order to determine whether the level of declarative knowledge of the sequence influenced significantly the learning effect observed in the task (see Table 5). The results of the analyses yielded a pattern identical to the one found with the group as a whole. The learning effect observed in the first analysis was therefore not due to the performance of subjects 
TABLE 5

Means (and Standard Error) for the Four Dependent Variables for the 14 Unaware Subjects in the Sequence Condition

\begin{tabular}{|c|c|c|c|c|c|}
\hline & Block 1 & Block 2 & Block 3 & Block 4 & Block 5 \\
\hline Total time & $27.03(1.80)$ & $25.35(2.01)$ & $22.46(1.56)$ & $17.73(2.25)$ & $20.04(2.43)$ \\
\hline Initial planning time & $12.30(1.29)$ & $12.15(1.47)$ & $11.94(1.57)$ & $8.90(1.32)$ & $9.13(1.10)$ \\
\hline Execution time & $14.73(1.45)$ & $13.21(2.11)$ & $10.53(1.10)$ & $8.84(1.45)$ & $10.91(1.72)$ \\
\hline Number of moves & $5.79(0.16)$ & $5.75(0.16)$ & $5.74(0.15)$ & $5.45(0.10)$ & $5.69(0.12)$ \\
\hline
\end{tabular}

who had acquired better declarative knowledge of the repeating sequence.

\section{Discussion}

The present study constitutes the first attempt to study the changes that occur over time while normal control subjects are acquiring the ability to solve problems using the Tower of London task. We used a sequence learning paradigm to compare the performance of subjects exposed to different problems on each trial to that of subjects presented with a repeating sequence of three problems. The results reveal that subjects in both the random and sequence conditions improved their performance on this task with practice. This suggests that exposure to such problems can, by itself, trigger changes in a subject's capacity to use the mental operations necessary to solve this type of problem. A careful analysis of the fluctuations in different dependent measures also shed light on the cognitive mechanisms underlying the increase in performance on the Tower of London task. Finally, the present findings show that, after several repetitions of a sequence of Tower of London problems, the subjects further increased their efficacy at developing specific sets of rules and strategies to perform this task, over and above their general ability at solving problems.

\section{General Skill Learning}

The first objective of this study was to examine the development of a general ability with practice using the Tower of London task. Subjects in the random condition exhibited significant learning of the skill necessary to solve Tower of London problems more efficiently, as evidenced by significant decreases in the four dependent variables measured on this task. Although subjects in the sequence condition were exposed to repeating problems, our results suggest that they too acquired the general rules, procedures, and strategies applicable to any Tower of London problem. Indeed, these subjects also demonstrated a significant increase in performance from Blocks 1 to 5. Both groups reached a similar level of general ability after practice, as evidenced by the fact that no significant difference in the performance of the two groups was observed in any of the dependent variables on the first and last blocks of practice (Blocks 1 and 5).
Our findings are in accord with a large number of studies that have examined cognitive skill learning in normal control subjects using a variety of paradigms (see Newell \& Rosenbloom, 1981, for a review). Our results are also consistent with previous studies using the Tower of Hanoï, which have shown that subjects exhibit a significant improvement in solving the puzzle after repeated exposure to this task (Beatty et al. 1987; Butters et al., 1985; Cohen et al., 1985; Saint-Cyr et al., 1988). Thus, the present pattern of findings indicates that this new version of the Tower of London task constitutes a valid measure of an individual's ability to acquire a new cognitive skill. Because this task allows the possibility of studying performance using different dependent variables and to present subjects with a large number of problems varying in difficulty level, the Tower of London test is also thought to represent an adequate laboratory measure of the cognitive skills that are used in everyday life.

\section{Cognitive Processes Involved in Skill Acquisition}

The second objective of this experiment was to shed some light on the different learning mechanisms elicited during acquisition of the cognitive skill under study. One of the main components of skill acquisition put forward by the present results is that the learning of this task through practice is characterized by a significant acceleration in the time taken to elaborate mentally a solution to the Tower of London problems. As the skill developed, subjects spent less time in the initial planning phase. Previous neuropsychological studies (Owen, 1997; Owen et al., 1996) have used a similar measure of the "thinking time" used to perform Tower of London problems of varied degrees of complexity. These studies have shown a positive correlation between longer thinking time and increasing difficulty of problems. Whereas these studies looked at performance at one point in time, our results illustrate changes in initial planning time over time during a training period. Indeed, our data suggest that the proficiency of this process is improved with learning. Because the subjects were instructed to try to plan a solution to the problem in order to complete it in the minimum number of moves, it is reasonable to believe that this dependent measure provides a good indicator of the subjects' planning ability to solve such problems. 
Such a pattern of findings is in accord with other studies on cognitive skill learning that have reported a reduction in the subjects' latency to respond to electronic problems using the Digital Logic Gates Test (Woltz, 1988) and a shorter period of time needed to give a response to problems requiring complex mathematical operations (Charness et al., 1988).

Another important mechanism of skill acquisition observed in this study was an increase in efficiency at carrying out a solution. Subjects showed a significant reduction both in terms of time to execute the solution and in the number of moves needed to complete the Tower of London problems after practice. This replicates the findings from studies using the Tower of Hanoï task, which indicate that normal control subjects can learn to solve this puzzle using a decreasing number of disk displacements (Beatty et al., 1987; Butters et al., 1985; Cohen et al., 1985; Saint-Cyr et al., 1988). Our results, therefore, suggest that as the skill develops with practice, solutions come to be rapidly transformed into more effective plans of actions. In turn, these actions are carried out more easily and rapidly, and with fewer superfluous behaviors.

The fact that subjects improved their execution of the solutions is also suggestive of amelioration in the efficiency of subsequent planning processes (i.e., planning activities occurring after the first move was initiated). Indeed, even though subjects were asked to initially plan the solution to the problems before initiating a first move, there is evidence to suggest that further planning occurs once the first move is completed (Owen, 1997; Owen et al., 1996). We therefore believe that the decrease observed in execution time as a function of practice reflects not only a decrement in the time needed to complete the displacements, but also an acceleration in subsequent planning processes.

We propose that, with practice, subjects learn to combine and coordinate more easily, and with increasing fluidity, the different procedures involved in the completion of the Tower of London task. This proposition falls in line with Charness and Campbell's (1988) finding that the time spent on resolving individual parts of a mental calculation task accounted for only 20 to $33 \%$ of the speed-up in performance in terms of the total time needed to solve the whole mathematical operation. This suggests that a major portion of the variance attributable to the improvement seen in the subjects' performance with training is due to increased efficiency in combining and managing the individual parts of the task and in activating the operations that allow subjects to make more efficient links between the different components of the algorithm.

Although it is difficult to identify the nature of such linking processes, one possible candidate in the Tower of London task is the subjects' working memory capacity. Indeed, working memory is a major contributor in this task as it requires an active search of solutions and the generation of plans of actions, placing a significant load on short-term memory processes (Owen, 1997; Owen et al., 1992, 1996). Subjects need constantly to monitor and evaluate their moves, and to keep track mentally of the plans and actions they made. It is highly probable that working memory is the major intermediate process that allows easy and rapid switching back and forth between the planning and execution phases to more effectively generate and adjust plans and moves. With skill acquisition, on-line evaluation and readjustment of plans and execution could be made more effectively with information flowing faster through working memory and in a more efficiently organized manner.

Unfortunately, the design of this experiment did not allow us to monitor the development of specific strategies, nor did it enable us to quantitatively assess their types and frequency during problem solving. In future experiments it may be interesting to use recognitionoriented measures of strategy development. Based on the literature on problem solving, however, it is possible to suggest some of the ways subjects may be approaching Tower of London problem solving. Indeed there exist global strategies, commonly called beuristics, which can be applied to a variety of problem-solving situations and can also be applied to Tower of London resolution. A heuristic, as defined by Anderson (1990), is a rule of thumb that often (but not always) leads to a solution. This type of rule can be contrasted with algorithms, which are guaranteed to result in the solution of a problem. Some common heuristics include the following: 1) The differencereduction method (or hill-climbing) involves choosing operators that will reduce the difference between the actual and goal state. As an example, in Figure 1-a, moving the blue ball to the bottom of the second column reduces the difference by one step between the working and model displays; 2) Means-end analysis relies on a similar principle, but includes the setting of subgoals to reduce the difference between the actual and goal state; 3) The working-backward method involves breaking a goal into a set of subgoals whose solutions imply a solution of the original goal; 4) Problem solving by analogy is a form of episode- or example-based learning and involves using the structure of the solution of one problem to solve another; 5) Finally, trial-and-error learning is also used by some participants in problem solving. While this is not directly a heuristic, such an approach often triggers the use of a rule of thumb once participants realize they are closer to a solution. With respect to the Tower of 
London, this can be seen in participants who displace balls on the screen seemingly at random until they realize they are on the path to a solution, whereby another heuristic is often applied.

Though it is possible to identify the use of such strategies in participants solving the Tower of London, the application of these heuristics is not a conscious process in that participants do not actively employ one rule or another. Furthermore, there is a great deal of variation in the heuristics used from one individual to another, and even within the same individual solving different Tower of London problems. Finally, any combination of heuristics may be used by one person and within one problem. Unfortunately, it is very difficult to determine the exact way a problem is solved without a step-by-step verbalized description by the solver.

It is our belief that the increasingly efficient application of the above mentioned heuristics eventually leads to the establishment of specific production rules for solving the Tower of London task, which, with practice, result in procedural learning. Anderson (1997) has proposed a four-stage model of skill acquisition involving four overlapping stages: Participants first start with analogy to study examples; with increasing practice, they develop abstract rules, and gradually move to the use of production rules. Finally, they perform a task by retrieval of specific examples. This distinction between problem solving by analogy or by abstraction of rules is akin to the comparison cited in the problem-solving literature between episode- and rule-based learning (Caplan \& Schooler, 1990).

We believe that the way in which participants acquire the skill of solving the Tower of London is through a combination of declarative and procedural knowledge similar to that outlined in Anderson's cognitive skill-learning theory. Indeed, participants initially have only a few Tower of London examples on which to base their strategies for problem solving. As practice evolves and they acquire an increasingly large pool of experience, they learn to use previous experience or similar examples to guide them and begin to apply problem-solving heuristics. The application of such heuristics in turn leads to the development of abstract rules specific to the Tower of London task. These rules enable them to near their goal. For instance, an individual might realize that a ball that must be placed on the bottom of a column has to be kept "free" such that it can be placed first, and therefore should either be alone or on top of another ball. With practice, such abstract rules come to be combined more effectively and rapidly and result in procedural learning. At a concrete level, this learning is reflected by changes in the behavioural data. As such, our findings allow us to suggest at least four mechanisms underlying the acquisi- tion of a problem-solving skill using the Tower of London: 1) an acceleration of the planning phase where subjects construct a solution more effectively, probably through faster analysis and comprehension of the problem, 2) an increase in efficiency in the execution phase where subjects come to carry out their plans more and more effectively with less superfluous behaviours, 3) an acceleration in subsequent planning processes where plans are adjusted or new ones are elaborated, and finally, 4) a tuning of intermediate processes, possibly working memory capacities, that allow more effective monitoring of the subjects' behaviour in order to link together the appropriate plans and strategies needed for the intended actions. Finally, in time and with substantial exposure to Tower of London problems, participants can refer back to specific examples from the pool of problems and thus even more rapidly apply a solution. As we will see in the following section, this may reflect the particular type of learning observed when a sequence is included in the Tower of London problem set.

\section{Sequence Learning}

The third objective of the present study was to address the issue of specificity of the cognitive skill that was acquired with practice on the Tower of London task. Our results indicate that the introduction of a repeating sequence of elements in a cognitive task can enhance learning. Indeed, the learning curve was significantly different when the two groups of subjects were compared. Subjects in the sequence condition demonstrated a significant improvement on measures of total time, initial planning time, execution time, and number of moves between Blocks 2 and 4, when the sequence was presented. Subjects in the random condition, on the other hand, did not show such improvement from Block 2 to Block 4. Furthermore, subjects in the sequence condition demonstrated a significant negative transfer from Block 4 to Block 5, in terms of the total time, execution time, and the number of moves when the sequence was removed, whereas no such change was observed in the random condition. By contrast, subjects did not show a deterioration in their measure of initial planning time from Block 4 to Block 5. This may suggest that subjects did not notice that the problems were different from those of the previous blocks, as they did not take significantly more time to think or plan before initiating their first moves. However, the change in the number of moves, execution, and total time indicates that subjects were less efficient when different problems were presented on each trial and that they needed to engage in more subsequent planning activities.

Thus, the results of this experiment provide the first 
evidence that a cognitive skill can be measured with a sequence learning paradigm. There is now general agreement that the ability to acquire a sequence of events or actions is an essential part of skill learning (Clegg, DiGirolamo, \& Keele, 1998). For example, the serial reaction time task has been repeatedly used to measure one's capacity to acquire a motor skill composed of sequences of movements (e.g., Doyon, 1997; Doyon et al., 1997, 1998; Nissen \& Bullemer, 1987). Sequence learning paradigms are useful in that they are relatively simple to implement and allow easy manipulation of the stimuli. In such a design, changes in improvement seen over time can therefore be readily associated with the presence or absence of the sequence. Our results are in accord with those of Nissen and Bullemer (1987) who reported that a significant decrease in reaction time on a visuomotor sequence learning task can be observed when the presentation of stimuli follow a specific sequence, but not when stimuli are displayed in a random order. This suggests that the learning of a specific sequence of events can be dissociated from the more general ability to respond to stimuli that is acquired in the random condition. Similarly, the results of our study support the idea that additional improvement in performance due to the presentation of repeated items can be attributed to the acquisition of a skill that is specific to the sequence of problems. This specific skill can develop over and above a more general ability at executing any Tower of London problem. Indeed, though the amount of practice was the same in both the random and sequence conditions, we believe that the learning experience is different for both groups and that greater exposure to the same problem may potentiate learning. Thus, it is possible that repetition of problems enables accelerated learning by priming the access to specific solution paths, a process from which participants cannot benefit when solving problems in the random condition. In this way, participants may develop knowledge of production rules more rapidly because the solutions to the sequence problems are always the same. The solution path applied to a sequential problem is, however, very specific and cannot directly be generalized to all problems. Thus, each time subjects are presented with a repeating five-move problem, they can apply exactly the same solution and know that it will work, but when presented with a random fivemove problem, for example in Block 5, the rule previously used for sequence problems may not apply. This forces subjects to resort back to the same problem-solving mechanisms as those in the random condition, as outlined above.

Another aspect that differentiates learning in the sequence and random conditions is that participants in the sequence condition have the possibility to solve repeating problems by using past examples as a whole, though this is not necessarily a conscious process. This contrasts with those in the random condition who can only use parts of a previous example when solving problems by analogy. Additionally, participants in the sequence condition may benefit from feature-analysis during problem solving, whereas those in the random condition profit only from a heuristic-based approach. Sequence learners may begin to pay attention to the repeating disposition of balls and order of colours in both the working and model displays, thus giving them additional sources of information during learning.

The acquisition of sequential information can occur in a variety of tasks and can involve both nondeclarative processes or declarative processes (Grafton, Hazeltine, \& Ivry, 1995). It is our belief that the acquisition of any skill that is cognitive in nature requires a complex amalgam of both these processes. In the present experiment, noticing the repetition may have constituted a piece of declarative information that could have contributed to an enhancement in learning. Certainly, awareness of a repetition may have caused participants to pay closer attention either to the abstract rules necessary to solve a particular repeating problem, or to the surface characteristics (feature analysis). This is more likely to be the case in the easier four-move problems simply because the solution to these problems is easier to recognize and places less of a load on working memory. However, it is likely that the increase in performance with the repeating problems was not simply due to the fact that subjects developed some explicit knowledge of the solutions to these problems with practice. Indeed, even though most subjects noticed that some problems were repeated, very few were able to give details about them. This indicates that subjects could not have generated the solution to the problems solely on the basis of explicit knowledge of the moves to be executed. Since subjects had to go through the problem-solving process on every trial, they had to engage the procedural learning operations that allow the elaboration of an effective strategy. These findings are consistent with studies demonstrating that amnesic patients can acquire cognitive skills normally despite having no explicit recollection of the information learned over the training sessions (Beaunieux et al., 1998; Brooks \& Baddeley, 1976; Charness et al., 1988; Cohen et al., 1985; Gabrieli, Keane, \& Corkin, 1987; McGlinchey-Berroth et al., 1989). They are further consistent with the observations made by Kirkhart (2001) in a study designed to examine the nature and function of declarative knowledge in an implicit and explicit version of an artificial grammar task. Indeed, the author suggests that, "declarative 
statements generated for the implicit task were posthoc descriptions of the most commonly seen physical features..." In this sense, it is possible in the Tower of London task that information reported by subjects may be a description of behaviour emitted (related either to a heuristic or to the physical features of the task) during problem solving rather than being information that was available and helpful to the participant during learning. In order to test such a hypothesis, an "explicit version" of the Tower of London task could be developed in which participants are immediately given a set of rules that can guide their problem-solving attempts, and compared to an "implicit version" such as that used in the present experiment. Such a comparison may help to distinguish when declarative information is the source of behaviour (explicit learning) and when it is not (implicit learning).

Conclusion

In conclusion, the present findings provide evidence that the Tower of London task is not only useful as a tool to measure procedural learning, but that it also allows to gain insight into the mechanisms that underlie cognitive skill acquisition. In this new version of the Tower of London task, subjects learned to use the proper strategies, rules, and procedures pertaining to this task with practice in order to plan the best solutions to the problems and to carry them out more effectively. Furthermore, our findings demonstrate that the use of sequence learning paradigms enables the study of the development of a specific set of mental operations that can be differentiated from a more general ability at solving the Tower of London task. This new way of studying cognitive skill learning could be helpful in elucidating other phases of learning such as consolidation and retention, and could also be combined with modern brain imaging techniques to examine the neural substrates of the different mechanisms involved at different phases of learning of cognitive skilled behaviour. Finally, this new task could be useful to develop training programs to enhance performance on cognitive tasks after damage to the human brain.

This manuscript is based on work that served as partial fulfillment of the requirements for a master's degree to Marie-Christine Ouellet at Université Laval. We wish to thank all the volunteers who participated in this study as well as Joanne Roy, Isabelle Deaudelin, and Rhonda Amsel for help and advice. Experiments were supported by grants from the Natural Sciences and Engineering Research Council of Canada and from the Fonds de Recherche en Santé du Québec.

Correspondance concerning this article should be addressed to Julien Doyon, Département de psychologie,
Université de Montréal, C.P. 6128 succursale Centre-Ville, Montréal, Québec H3C 3J7 (E-mail: julien.doyon@ umontreal.ca).

\section{References}

Anderson, J. R. (1990). Acquisition of cognitive skill. Psychological Review, 89, 369-406.

Anderson, J. R., Farrell, R., \& Sauers, R. (1984). Learning to program LISP. Cognitive Science, 8, 87-129.

Anderson, J. R., \& Fincham, J. M. (1994). Acquisition of procedural skills from examples. Journal of Experimental Psychology: Learning, Memory and Cognition, 20, 13221340.

Anderson, J. R., Fincham, J. M., \& Douglass, S. (1997). The role of examples and rules in the acquisition of a cognitive skill. Journal of Experimental Psychology. Learning, Memory and Cognition, 23, 932-945.

Anderson, J. R., Greeno, J. G., Kline, P. J., \& Neves, D. M. (1981). Acquisition of problem solving skills. In J. R. Anderson (Ed.), Cognitive skills and their acquisition. Hillsdale, NJ: Erlbaum.

Anzai, Y., \& Simon, H. A. (1979). The theory of learning by doing. Psychological Review, 86, 124-140.

Baker, S. C., Rogers, R. D., Owen, A. M., Frith, C. D., Dolan, R. J., Frackowiak, R. S. J., et al. (1996). Neural systems engaged by planning: A PET study of the Tower of London task. Neuropsychologia, 34, 515-526.

Beatty, W. W., Salmon, D. P., Bernstein, N., Martone, M., Lyon, L., \& Butters, N. (1987). Procedural learning in a patient with amnesia due to hypoxia. Brain and Cognition, 6, 386-402.

Beaunieux, H., Desgranges, B., Lavalee, C., De la Sayette, V., Lechevalier, B., \& Eustache, F. (1998). Preservation of cognitive procedural memory in a case of Korsakoff's syndrome: Methodological and theoretical insights. Perceptual and Motor Skills, 86, 1267-1287.

Berry, D. C., \& Broadbent, D. E. (1984). On the relationship between task performance and associated verbalizable knowledge. Quarterly Journal of Experimental Psychology, 36, 209-231.

Brooks, D. N., \& Baddeley, A. D. (1976). What can amnesic patients learn? Neuropsychologia, 14, 111-122.

Butters, N., Wolfe, J., Martone, M., Granholm, E., \& Cermak, L. S. (1985). Memory disorders associated with Huntington's disease: Verbal recall, verbal recognition and procedural memory. Neuropsychologia, 23, 729-743.

Campbell, J. I. D., \& Graham, D. J. (1985). Mental multiplication skill: Structure, process, and acquisition. Canadian Journal of Psychology, 39, 338-366.

Caplan, L. J., \& Schooler, C. (1990). Problem solving by reference to rules or previous episodes: The effects of organized training, analogical models, and subsequent complexity of experience. Memory \& Cognition, 18, 215-227.

Carlson, A. R., Sullivan, A. M., \& Schneider, W. (1989). 
Practice and working memory effects in building procedural skill. Journal of Experimental Psychology: Learning, Memory and Cognition, 15, 517-526.

Charness, N., \& Campbell, J. I. D. (1988). Acquiring skill at mental calculation in adulthood: A task decomposition. Journal of Experimental Psychology: General, 117, 115129.

Charness, N., Milberg, W., \& Alexander, M. P. (1988). Teaching an amnesic a complex cognitive skill. Brain and Cognition, 8, 253-272.

Cheng, P. W. (1985). Restructuring versus automaticity: Alternative accounts of skill acquisition. Psychological Review, 12, 414-423.

Clegg, B. A., DiGirolamo, G. J., \& Keele, S. W. (1998). Sequence learning. Trends in Cognitive Sciences, 2, 275281.

Cohen, N. J., \& Corkin, S. (1981). The amnesic patient H.M.: Learning and retention of a cognitive skill. Society for Neuroscience Abstracts, 7, 235.

Cohen, N. J., Eichenbaum, H., Deacedo, B. S., \& Corkin, S. (1985). Different memory systems underlying acquisition of procedural and declarative knowledge. Annals of the New York Academy of Science, 444, 54-71.

Daum, I., Schugens, M. M., Spieker, S., Poser, U., Schonle, P. W., \& Birbaumer, N. (1995). Memory and skill acquisition in Parkinson's disease and frontal lobe dysfunction. Cortex, 31, 413-432.

DeGroot, A. D. (1965). Thought and choice in chess. The Hague: Mouton.

Doyon, J. (1997). Skill learning. International Review in Neurobiology, 41, 273-294.

Doyon J., Gaudreau D., Laforce R. Jr., Castonguay M., Bedard P. J., Bedard F., et al., (1997). Role of the striatum, cerebellum, and frontal lobes in the learning of a visuomotor sequence. Brain and Cognition 34(2), 21845.

Doyon, J., Laforce, R., Jr., Bouchard, J. P., Gaudreau, D., Roy, J., Poirier, M., Bédard, P. J., Bédard, F., Bouchard, J.-P. (1998). Role of the striatum, cerebellum and frontal lobes in the automatization of a repeated visuomotor sequence of movements. Neuropsychologia, 36, 625-641.

Ericsson, K. A. (1985). Memory skill. Canadian Journal of Psychology, 39, 188-231.

Fasotti, L., Eling, P. A., \& van Houtem, J. (1994). Categorization of arithmetic word problems by normals, frontal and posterior-injured patients. Journal of Clinical and Experimental Psychology, 16, 723-733.

Fitts, P. (1962). In R. Glaser (Ed.), Training research and eduction. Pittsburgh, PA: University of Pittsburgh Press.

Gabrieli, J. D. E., Keane, M. M., \& Corkin, S. (1987). Acquisition of problem-solving skills in global amnesia. Society for Neuroscience Abstract, 13, 1455.

Glisky, E. L., \& Schacter, D. L. (1988). Long-term retention of computer learning by patients with memory disorders.
Neuropsychologia, 26, 173-178.

Glisky, E. L., \& Schacter, D. L. (1989). Extending the limits of complex learning in organic amnesia: Computer training in a vocational domain. Neuropsychologia, 27, 107120.

Glisky, E. L., Schacter, D. L., \& Tulving, E. (1986). Computer learning by memory-impaired patients: Acquisition and retention of complex knowledge. Neuropsychologia, 24 , 313-328.

Grafton, S. T., Hazeltine, E., \& Ivry, E. E. (1995). Functional mapping of sequence learning in normal humans. Journal of Cognitive Neuroscience, 7, 497-510.

Heller, J., \& Reif, F. (1984). Prescribing effective human problem solving: Problem description in physics. Cognition E Instruction, 2, 191-203.

Heuer, H. (1996). Dual-task performance. In O. Nuemann \& A. F. Sanders (Eds.), Handbook of perception and action, Vol. 3: Attention (pp. 113-153). London: Academic Press.

Kirkhart, M. W. (2001). The nature of declarative and nondeclarative knowledge for implicit and explicit learning. The Journal of General Psychology, 128, 447-461.

Knowlton, B. J., Ramus, S. J., \& Squire, L. R. (1992). Intact artificial grammar learning in amnesia: Dissociation of classification learning and explicit memory for specific instances. Psychological Science, 3, 172-179.

Knowlton, B. J., \& Squire, L. R. (1994). The information acquired during artificial grammar learning. Journal of Experimental Psychology: Learning, Memory, and Cognition, 20, 79-91.

Larkin, J. H. (1985). Understanding problem representation and skills in physics. In S. F. Chipman, J. W. Degal, \& R. Glaser (Eds.), Thinking and learning skills: Vol. 2 Research and open questions. Hillsdale, NJ: Erlbaum.

Lewicki, P., Hill, T., \& Bizot, E. (1988). Acquisition of procedural knowledge about a pattern of stimuli that cannot be articulated. Cognitive Psychology, 20(1), 24-37.

Logan, G. D. (1985). Skill and automaticity: Relations, implication and future directions. Canadian Journal of Psychology, 39, 367-386.

Logan, G. D. (1988). Toward an instance theory of automatization. Psychological Review, 95, 492-527.

McGlinchey-Berroth, R., Milberg, W. P., \& Charness, N. (1989). Learning of a complex arithmetic skill in dementia: Further evidence for a dissociation between compilation and production. Cortex, 25, 697-705.

Morris, R. G., Downes, J. J., Sahakian, B. J., Evenden, J. L., Heald, A., \& Robbins, T. W. (1998). Planning and spatial working memory in Parkinson's disease. Journal of Neurology, Neurosurgery, and Psychiatry, 51, 757-766.

Newell, A., \& Rosenbloom, P. S. (1981). Mechanisms of skill acquisition and the law of practice. In J. R. Anderson (Ed.), Cognitive skills and their acquisition (pp. 1-55). Hillsdale, NJ: Lawrence Erlbaum Associates.

Nissen, M. J., \& Bullemer, P. (1987). Attentional require- 
ments of learning: Evidence from performance measures. Cognitive Psychology, 19, 1-32.

Owen, A. M. (1997). Cognitive planning in humans: Neuropsychological, neuroanatomical and neuropharmacological perspectives. Progress in Neurobiology, 53, 431-450.

Owen, A. M., Downes, J. J., Sahakian, B. J., Polkey, C. E., \& Robbins, T. W. (1990). Planning and spatial working memory following frontal lobe lesions in man. Neuropsychologia, 28, 1021-1034.

Owen, A. M., \& Doyon, J. (1999). The cognitive neuropsychology of Parkinson's disease: A functional neuroimaging perspective. Advances in Neurology, 80, $49-56$.

Owen, A. M., Doyon, J., Petrides, M., \& Evans, A. C. (1996). Planning and spatial working memory: A positron emission tomography study in humans. European Journal of Neuroscience, 8, 353-364.

Owen, A. M., James, M., Leigh, P. N., Summers, B. A., Marsden, C. D., Quinn, N. P., et al. (1992). Fronto-striatal cognitive deficits at different stages of Parkinson's disease. Brain, 115, 1727-1751.

Pauli, P., Lutzenberger, W., Rau, H., Birbaumer, N., Rickard, T. C., Yaroush, R. A., et al. (1994). Brain potentials during mental arithmetic: Effects of extensive practice and problem difficulty. Cognitive Brain Research, 2, 21-29.

Pirolli, P. L., \& Anderson, J. R. (1985). The role of learning from examples in the acquisition of recursive programming skills. Canadian Journal of Psychology, 39, 240272 .

Reber, A. S., \& Millward, R. B. (1971). Event tracking in probability learning. American Journal of Psychology, 84, 85-99.

Reber, P. J., \& Kotovsky, K. (1997). Implicit learning in problem solving: The role of working memory capacity. Journal of Experimental Psychology: General, 126 (2),
178-203.

Rosenbloom, P., \& Newwell, A. (1986). The chunking of goal hierarchies: A generalized model of practice. In R. S. Michalski, J. G. Carbonel, \& J. M. Mitchel (Eds.), Machine learning II: An artificial intelligence approach. Los Altos, CA: Kaufman.

Saint-Cyr, J. A., Taylor, A. E., \& Lang, A. E. (1988). Procedural learning and neostriatal dysfunction in man. Brain, 111, 941-959.

Shallice, T. (1982). Specific impairments of planning. Philosophical Transactions of the Royal Society of London, B 298, 199-209.

Shiffrin, R. M., \& Dumais, J. T. (1981). The development of automatisation. In J. R. Anderson (Ed.), Cognitive skills and their acquisition (pp. 111-139). Hillsdale, NJ: Erlbaum.

Squire, L. R., \& Frambach, M. (1990). Cognitive skill learning in amnesia. Psychobiology, 18, 109-117.

Vanier, M. (1991). Test de la Tour de Londres: Évaluation de la capacité de planification. Institut de réadaptation de Montréal, École de réadaptation de l'Université de Montréal.

Wechsler, D. (1987). Wechsler Memory Scale-Revised. New York: Psychological Corporation.

Winter, W. E., Broman, M., Rose, A. L., \& Reber, A. S. (2001). The assessment of cognitive procedural learning in amnesia: Why the Tower of Hanoi has fallen down. Brain and Cognition, 45, 79-96.

Woltz, D. J. (1988). An investigation of the role of working memory in procedural skill acquisition. Journal of Experimental Psychology: General, 117, 319-331.

Yap, R. L., \& van der Leij, A. (1994). Testing the automatisation deficit hypothesis of dyslexia via a dual-task paradigm. Journal of Learning Disabilities, 27, 660-665.

Sommaire

Cette étude avait pour but d'investiguer l'apprentissage d'une habileté cognitive en examinant le cours de l'apprentissage, par la pratique, d'une nouvelle habileté de résolution de problèmes et de planification. À cette fin, une version informatisée de la tâche de la Tour de Londres a été utilisée. Dans cette tâche, les participants doivent déplacer des boules de couleurs dans trois colonnes afin de reproduire un modèle donné dans un nombre minimum de mouvements. Trente-six participants en bonne santé ont résolu cinq blocs de 15 problèmes à trois niveaux de difficulté $(4,5$ ou 6 mouvements), pour un total de 75 problèmes. Un problème à quatre mouvements était toujours suivi d'un problème à six mouvements, et ensuite d'un problème à cinq mouvements. Les participants étaient assignés soit à une condition " aléatoire " ou à une condition
" séquence ". Dans la condition " aléatoire ", les problèmes étaient présentés de façon non-répétitive et différaient donc à travers les cinq blocs de pratique. Dans la condition "séquence ", deux blocs de problèmes différents ont aussi été présentés (un au début [Bloc 1] et un à la fin [Bloc 5]). Toutefois, dans les blocs 2, 3 et 4, une séquence de trois problèmes répétés était présentée à l'insu des sujets. Pour mesurer les changements comportementaux, les indices de temps d'exécution, temps de planification et temps total, ainsi que le nombre de mouvements effectués ont été utilisés. À travers les blocs de pratique, la performance des participants s'est améliorée du Bloc 1 au Bloc 5, et ce dans les deux conditions. De plus, un effet d'apprentissage distinct a été noté en lien avec la séquence répétée. Ainsi, la performance des participants s'est également 
améliorée du Bloc 2 au Bloc 4, mais ce seulement pour les individus assignés à la condition "séquence " et non pas pour ceux dans la condition "aléatoire ". L'analyse des résultats démontre que trois mécanismes supportent le développement de l'habileté à résoudre ce type de problèmes, soit une accélération de la phase de réflexion ou de planification, une exécution plus efficace des plans élaborés et une accélération des processus intermédiaires permettant le suivi et l'autocorrection de la performance. Ensemble, les données suggèrent qu'une habileté spécifique, reflétant l'apprentissage procédural de stratégies, de règles et de procédures relié à des problèmes répétitifs peut se développer au-delà d'un apprentissage d'habileté plus général en ce qui concerne la résolution de problèmes de planification cognitive avec la pratique. 